\title{
Investigations of face expertise in the social developmental disorders
}

Jason J.S. Barton, $\mathrm{MD}, \mathrm{PhD}, \mathrm{FRCPC}$

Rebecca L. Hefter, BSc Mariya V. Cherkasova, BSc

Dara S. Manoach, $\mathrm{PhD}$

Address correspondence and reprint requests to Dr. Jason J.S. Barton, Neuroophthalmology Section D, VGH Eye Care Center, 2550 Willow Street, Vancouver, BC Canada V5Z 3N9

jasonbarton@shaw.ca

\section{ABSTRACT}

Background: Patients with social developmental disorders (SDD), also known as autism spectrum disorders, may have impaired recognition of facial identity or facial expressions.

Objective: Our goal was to determine whether SDDs were characterized by loss of a perceptual mechanism responsible for face expertise, as current theories suggest that such a loss should be selective for upright faces, disproportionately affect the perception of facial configuration, and possibly be more severe in the eye region.

Method: We tested a group of 24 adult patients with SDD with an oddity paradigm that required them to detect changes in facial configuration or feature color, in either the eyes or the mouth, in both upright and inverted faces.

Results: One group of subjects with SDD with normal famous face recognition had only a mild reduction in accuracy and a normal pattern of inversion effects. A second group of subjects with SDD with impaired famous face recognition had a severe reduction of accuracy. This deficit was not limited to upright faces. It affected the perception of feature configuration and feature color to a similar degree and both eye and mouth changes were discriminated poorly in upright faces.

Conclusion: The impaired face recognition that is present in a subset of patients with social developmental disorders is accompanied by impaired face perception, and this impairment is not exclusive to upright faces, facial configuration, or the eye region. The reduced face processing skills in these subjects may be more consistent with recent computational models of face expertise than with classic dual-route hypotheses. Neurology ${ }^{\circledR}$ 2007;69:860-870

There is considerable debate about the status of face processing in subjects with social developmental disorders (SDD), which include conditions such as autism, Asperger disorder, and the social-emotional processing disorder. ${ }^{1}$ In social interactions, the human face communicates social engagement by direction of gaze, emotional state by expression, and social context by identification of persons. The potential relevance of visual perception and in particular face processing skills to social behavior is suggested by reports of SDD-like features in patients with childhood-onset prosopagnosia, ${ }^{2-5}$ visual loss, ${ }^{6-11}$ and apperceptive visual agnosia. ${ }^{12,13}$ On the other hand, others argue that, even without a primary perceptual deficit, the presence of an SDD may impair the acquisition of normal face expertise during childhood. ${ }^{14-17}$ Since the ability to discriminate subtle differences between faces develops during childhood and requires exposure and interest ${ }^{18}$ the development of this perceptual skill may be hampered by a social apathy that may extend to the avoidance of looking at faces. ${ }^{19,20}$ A number of studies have documented difficulties with recognition of known faces ${ }^{21}$ and new faces ${ }^{22}$ and abnormal face-induced responses in event-related potentials ${ }^{23}$ and magnetoencephalography. ${ }^{24}$

Additional support for impaired face processing in SDD comes from functional imag-

From the Department of Neurology (J.J.S.B., R.L.H., M.V.C., D.S.M.), Beth Israel Deaconess Medical Center and Harvard Medical School, Boston, MA; Division of Neurology and Departments of Psychology, Ophthalmology, and Visual Sciences (J.J.S.B.), University of British Columbia, Vancouver, Canada; and Department of Psychiatry (D.S.M.), Massachusetts General Hospital, Harvard Medical School, and Athinoula A. Martinos Center for Biomedical Imaging, Boston.

Supported by NIMH grant 1R01 MH069898, CIHR grant MOP-77615, the Canada Research Chair program, and a Michael Smith Foundation for Health Research Senior Scholarship to J.B.

Disclosure: The authors report no conflicts of interest. 
ing studies. In healthy subjects, faces activate a network of areas, including the occipital face area, the fusiform face area, and the superior temporal sulcus. ${ }^{25}$ Particularly well studied is the fusiform face area, which is activated selectively by faces over other objects. Whether this reflects a specific face module or simply a region of developed perceptual expertise can be debated $^{26,27}$; nevertheless, in either case the presence of a fusiform face area can be considered a marker of specialized face processing. There are reports that face stimuli fail to activate the fusiform face area in adults with autism or Asperger disorder. ${ }^{28-30}$ However, these findings are challenged by recent studies showing intact activation of the fusiform face area in autism..$^{31,32}$ These suggested that earlier results may have been due to motivational issues or failures to attend to faces in these patients; consistent with this hypothesis, a recent study showed that activity in the fusiform face area in autistic subjects correlated with the time spent fixating the eyes. ${ }^{33}$

Given the continuing controversy over the status of the fusiform face area in SDD, it is important to assess the performance of patients with SDD on behaviors that are likely related to the function of the fusiform face area. In healthy subjects, functional neuroimaging studies have suggested that the occipital face area and the fusiform face area may be involved in the discrimination of the structural aspects of faces relevant to facial identity. ${ }^{34}$ Prosopagnosic patients with lesions in the vicinity of the fusiform face area are impaired in the perception of facial configurationthat is, the relative position of features within a face. ${ }^{35}$ This is consistent with current concepts of normal face processing that suggest that face expertise may be characterized by facility at perceiving the overall configuration of a face. Furthermore, because this configurational expertise has developed through repeated exposure to upright faces, it is orientationdependent ${ }^{36-38}$; hence, one of the markers for face expertise is the inversion effect, in which upside-down faces are harder to process than upright ones. ${ }^{39,40}$ The classic dual-route hypothesis suggests that faces have the capacity to be processed by one of two systems: a generic object recognition system and a face-expert system. ${ }^{41}$ However, because the latter has evolved over years of continued training with upright faces, it is orientation-dependent. Thus the greater difficulty with inverted faces arises because, while both upright and inverted faces may use generic object processing, only upright faces have the additional benefit of access to expert face-processing mechanisms.

Given these data, one might hypothesize that, if subjects with SDD failed to develop normal face expertise, they may have relatively greater difficulty processing facial configuration than other types of facial information. Second, they may show a reduced inversion effect, in that their performance with upright faces should more resemble their performance with inverted faces, as generic object processing should operate similarly on both types of faces in the absence of more specialized face processing. Indeed, one possible outcome might even be an inverted inversion effect, in which subjects process upsidedown faces more efficiently than upright faces ${ }^{42,43}$ which some propose occurs through the removal of an inhibitory influence of expert mechanisms on the processing of inverted stimuli by generic mechanisms.

In addition to these two predictions driven by the dual-route model of face expertise, we wished to test for a third potential effect, one based mainly upon empirical observations in subjects with SDD. Autistic children are found to process the lower half of faces better than the upper half, whereas the reverse is true of healthy subjects, ${ }^{44}$ and recent fixation studies showed that autistic subjects avoid looking at the eyes. ${ }^{45}$ Given the importance of the eye region for social information, ${ }^{46}$ one might also hypothesize that subjects 
with SDD may have a specific failure to process perceptual data from the eyes. A potentially significant role for the eye region in expert face processing is also suggested by the fact that normal subjects engaged in a face identification task concentrate their fixations in the eye region ${ }^{47}$ and by a recent finding that one prosopagnosic subject showed a failure to process perceptual information from the eye region. ${ }^{48}$ Given these observations, we expected subjects with SDD to have a selective failure to process information from the eyes.

We examined these predictions by studying how a group of adult subjects with SDD discriminated differences in $\mathrm{fa}$ cial properties. First, we contrasted the perception of feature configuration with feature color and expected a selective deficit with the former ability. Second, we examined the perception of upright vs inverted faces to test the hypothesis that subjects with SDD would lack the expert advantage for upright faces. Finally, we expected a more pronounced deficit in perceiving changes in the eye vs mouth region. Since our prior study documented two groups of subjects with SDD, one with normal (SDD-1) and one with abnormal (SDD-2) face recognition skills, ${ }^{49}$ our final expectation was that the SDD-1 group would show less perceptual impairment on all of these measures than the SDD-2 group.

METHODS Subjects. The study was approved by the Committee on Clinical Investigations at Beth Israel Deaconess Medical Center. All subjects gave written informed consent after the experimental procedures had been fully explained according to the Declaration of Helsinki. We tested 24 adults with SDD who were recruited from adult outpatient clinics offering neuropsychological assessment in the Boston area. All of these subjects were living and working in the community without assistance, and are thus considered high-functioning. We limited our sample to age 16 and over because there is some evidence that face recognition skills may continue to mature during childhood. Subjects with histories of acquired brain disease or injury were excluded. Sixteen subjects were taking medications for mood disorders or attention deficit, including bupropion, fluoxetine, venlafaxine, methylphenidate, sertraline, and citalopram. Our SDD sample consisted of 7 female and 17 male subjects, with ages ranging from 16 to 48 years. As controls we tested 11 normal subjects ( 4 male and 7 female) with ages ranging from 17 to 36 years, who had been screened by questionnaire for the presence of neurologic or psychiatric disorders.

Diagnoses were made by the referring neuropsychologist and were confirmed by a second licensed neuropsychologist (D.S.M.) based on a thorough review of psychological, neuropsychological, and medical evaluations and supplemented by an interview with the subject and a parental informant whenever possible. We obtained detailed histories with attention to birth-related events, developmental milestones, emotional adjustment, social history, and family history. In addition, behavioral observations from the neuropsychological evaluation (see below) and the interview were recorded. Special attention was given to observations regarding paralinguistic communication ability including the use of eye contact, facial expression, and gesture. The supplemental interview and behavioral observations addressed the material covered by the Autism Diagnostic Interview-Revised (Short Edition) (ADI-R) ${ }^{50}$ in a format appropriate for adults, adolescents, and their parental informants.

Various diagnostic labels have been applied to developmental conditions that affect the processing of social and emotional information. These include Asperger disorder, autism, right hemisphere learning disability, nonverbal learning disability, and social-emotional processing disorder. This reflects a lack of consensus about diagnostic criteria and the different approaches used to evaluate the subjects (psychiatric, neuropsychological, behavioral). Nevertheless, these different criteria overlap considerably in the area of social dysfunction. This is probably best captured by criterion A in the Diagnostic and Statistical Manual of Mental Disorders (DSM-IV) diagnosis of Asperger disorder: namely, "qualitative evidence of impaired social interaction, manifest in non-verbal social behaviors, peer relationships, spontaneous social engagement, and social/emotional reciprocity." We considered this, along with the exclusion of other pervasive developmental disorders and schizophrenia, to be the core criterion for the presence of an SDD.

Regarding specific diagnoses, our approach was planned to be neutral regarding the debate about diagnostic validity for separate SDD categories. We aimed to obtain sufficient information to determine whether subjects met criteria for each of three diagnostic categories: Asperger disorder, highfunctioning autism, and social-emotional processing disorder. We considered subjects to have SDD if they met Asperger criterion A and also additional criteria for at least one of these three syndromes (table 1). Further discussion of the details of these diagnostic criteria can be found in our previous reports on this cohort. ${ }^{49,51}$ A substantial number of our subjects fulfilled criteria for both Asperger disorder and social-emotional processing disorder. Subjects were classified as meeting criteria for Asperger disorder only $(\mathrm{n}=2)$, social-emotional processing disorder only $(\mathrm{n}=11)$, both Asperger disorder and social-emotional processing disorder $(\mathrm{n}=8)$, or high-functioning autism $(\mathrm{n}=3)$.

Perceptual classification of subjects with SDD. These subjects have had extensive testing of their face perception, which has been reported previously. ${ }^{49,51}$ These include standard neuropsychological instruments such as the Warrington Recognition Memory test, ${ }^{52}$ and the Benton Face Recognition test, ${ }^{53}$ as well as our own experimental tests of discrimination of famous from anonymous faces, ${ }^{54}$ and of 
Table 1 Diagnostic criteria for social developmental disorders

$\begin{array}{lllll}\text { Criterion } & \text { Autism } & \text { Asperger } & \text { SEPD } & \text { Asperger \& SEPD } \\ \text { Social impairment } & \text { Y } & \text { Y } & \text { Y } & \text { Y } \\ \begin{array}{l}\text { Significant impairment in functioning } \\ \text { (i.e. social, occupational) }\end{array} & \text { Y } & \text { Y } & \text { Y } & \text { Y } \\ \text { Abnormal language acquisition } & \text { Y } & \text { N } & \text { N } & \text { N } \\ \text { Repetitive behavior } & \text { Y } & \text { Y } & \text { Y } & \text { Y } \\ \begin{array}{l}\text { Right hemisphere dysfunction } \\ \text { (VIQ }>\text { PIQ by at least 10 points) }\end{array} & \text { N/A } & \text { N/A } & \text { Y }\end{array}$

SEPD $=$ socioemotional processing disorder; $\mathrm{Y}=$ criterion required; $\mathrm{N}=$ criterion absent; $\mathrm{N} / \mathrm{A}=$ criterion not applicable to diagnosis; VIQ = verbal IQ; PIQ = performance IQ.

facial imagery. ${ }^{55}$ (In addition, the averaged upright configuration perception data from this report were also presented in one of these prior studies. ${ }^{49}$ ) Cluster analysis confirmed at least two groups of subjects with SDD: one with normal face recognition (SDD-1) and one with abnormal face recognition (SDD-2). This was best typified by their scores on the test of famous face recognition, where the SDD-1 group had a mean d' of 3.30 (SD 0.40) and the SDD-2 group had a mean $\mathrm{d}^{\prime}$ of 1.58 (SD 0.48), compared to a mean $\mathrm{d}^{\prime}$ of 2.77 in controls. Prediction of perceptual group membership could not be made from traditional diagnostic labels of autism, Asperger disorder, or social emotional processing disorder. Hence in this report we analyze the data by perceptual group membership (SDD-1, $\mathrm{n}=8$ vs SDD-2, $\mathrm{n}=16$ ) rather than by diagnostic labels. The demographic data of these two groups are provided in table 2: there was a trend to slightly better performance IQ for SDD-1 $(p<0.057)$ but otherwise no significant difference in other parameters.

Stimuli. These have been described in our previous publications. ${ }^{35,38}$ The aim was to create face stimuli that differed in a stepwise quantitative fashion along four dimensions. Two of these were second-order spatial relations, or configurational properties: the vertical mouth position and the interocular distance (figure 1). The other two were feature changes: eye color and mouth color, which do not affect second-order spatial relations. Altered faces had to remain plausible, so that impressions of grotesqueness did not affect discrimination judgments. ${ }^{56}$

We used full-color digitized frontal images of the faces of one male and one female. Each facial image occupied a square of 250 by 250 pixels, which in the test sequences spanned 8.8 by 8.8 degrees of visual angle at the viewing distance of $57 \mathrm{~cm}$. The interocular distances of the two base images were similar, being 2.1 degrees for the female face and 2.3 degrees for the male face. Spatial manipulations of the images were done with Paintshop Pro 3.0 (Shareware). Three different target faces were constructed for each dimension. For eye displacement, interocular distance of the target faces was reduced by 8,12 , or 16 pixels from the base face. For mouth displacement, target faces had the mouth elevated by 6,8 , or 10 pixels. Each pixel corresponds to 2.1 minutes of visual angle. For eye or mouth color, brightness was increased by 9,12 , or $15 \%$, using Adobe Photoshop 5.0 (Adobe Systems Inc., www.adobe.com).

Protocol. Subjects sat $57 \mathrm{~cm}$ away from an Apple Multiscan 1705 monitor. The experiments were run with a Power Mac G4 computer. Before starting the experiment, subjects were told the nature of the four different manipulations (eye position, mouth position, eye color, mouth color) and shown examples of trials.

A trial stimulus consisted of three faces shown simultaneously in a triangular arrangement, with the faces equidistant from each other (figure 2). Two images were the base face, and the third was a target face, which occurred with equal probability at any of the three image positions. Viewing duration was constant at 2 seconds per trial. The subject's task was to indicate which face was the different one, with chance performance being $33 \%$ correct.

We constructed testing blocks using the Superlab 1.71 (Cedrus, www.superlab.com) program. One block had upright faces and one had inverted faces. The order of blocks was randomly determined for each subject. Each trial stimulus was presented nine times for each of the two test faces; thus there were 18 stimuli for each of the three gradations of change in each of the four dimensions altered, for a total of 216 trials per block.

Table 2 Demographic comparison between SDD-1 and SDD-2

$\begin{array}{lcc} & \begin{array}{l}\text { Normal face recognition } \\ \text { (SDD-1), mean (SD) }\end{array} & \begin{array}{c}\text { Impaired face recognition } \\ \text { (SDD-2), mean (SD) }\end{array} \\ \text { Age, y } & 38.4(5.9) & 32.8(11.5) \\ \text { Education, y } & 16.1(1.8) & 14.9(3.3) \\ \text { Parental socioeconomic status } & 2.1(1.4) & 1.7(1.0) \\ \text { IQ, verbal } & 120.0(17.7) & 115.3(19.8) \\ \text { IQ, performance } & 106.7(22.9) & 90.4(17.3) \\ \text { IQ, full scale } & 113.1(21.1) & 108.1(11.9)\end{array}$

$\mathrm{SDD}=$ social developmental disorders 


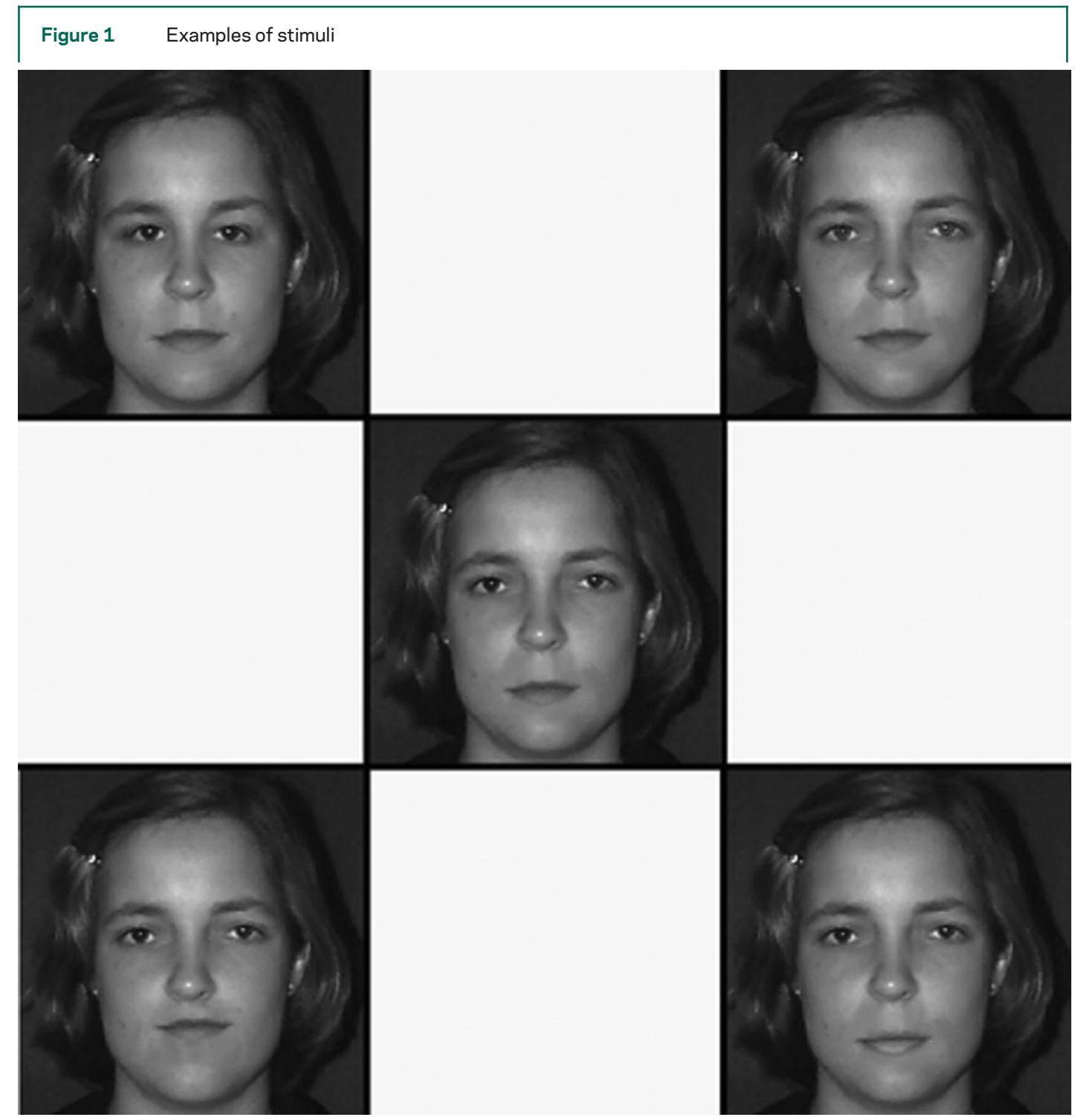

Middle image is the base female face. The top left image has a reduced interocular distance, the bottom left image has the mouth position shifted up. The top right image has a lighter eye color, the bottom right image has lighter mouth color.

Analysis. For each dimension in each orientation, we calculated mean accuracy using data for all degrees of change, with one exception. Pilot work had been conducted to determine the degree of change that would generate equivalent accuracy rates for the four different elements in upright viewing. However, the final results showed that changes in mouth color were more difficult than changes in the other elements for the normal subjects. Therefore we only used the data for the easiest level of change $(15 \%$ increase in brightness) for this dimension.

Accuracy rates were analyzed on JMP 3.2.6 (SAS Institute, www.jmp.com) using analysis of variance (ANOVA) with repeated measures, with main factors of face part (eye vs mouth), type of change (color vs spatial relation), face orientation (upright vs inverted), and subject group (control, SDD-1, SDD-2), and with subjects nested within group as a random effect.

RESULTS Overall effects of orientation, face part, and type of change. Looking at all groups combined, we reproduce some of the key findings we previously reported for normal subjects. There was a significant effect of face part because of greater accuracy for changes in the eyes than the mouth $\left(\mathrm{F}^{1,32}=62.5, p<0.0001\right)$. There was a significant effect for orientation with subjects more accurate for upright faces: this is the inversion effect $\left(\mathrm{F}^{1,32}=42.1, p<0.0001\right)$. There were significant interactions between orientation and face part $\left(\mathrm{F}^{1,32}=41.1, p<0.0001\right)$ with a significant inversion effect for the mouth $(t=9.13, p<$ 0.0001 ) but not the eyes. There was a significant interaction between orientation and type of change $\left(\mathrm{F}^{1,32}=15.6, p=0.0001\right)$, with a significant inversion effect for position $(t=7.38, p<$ $0.0001)$ and only a trend for color $(t=1.79, p=$ $0.074)$. There was also a significant three-way interaction between orientation, face part, and type of change $\left(\mathrm{F}^{1,32}=5.44, p<0.021\right)$ : while there 
Figure 2 Example of a trial

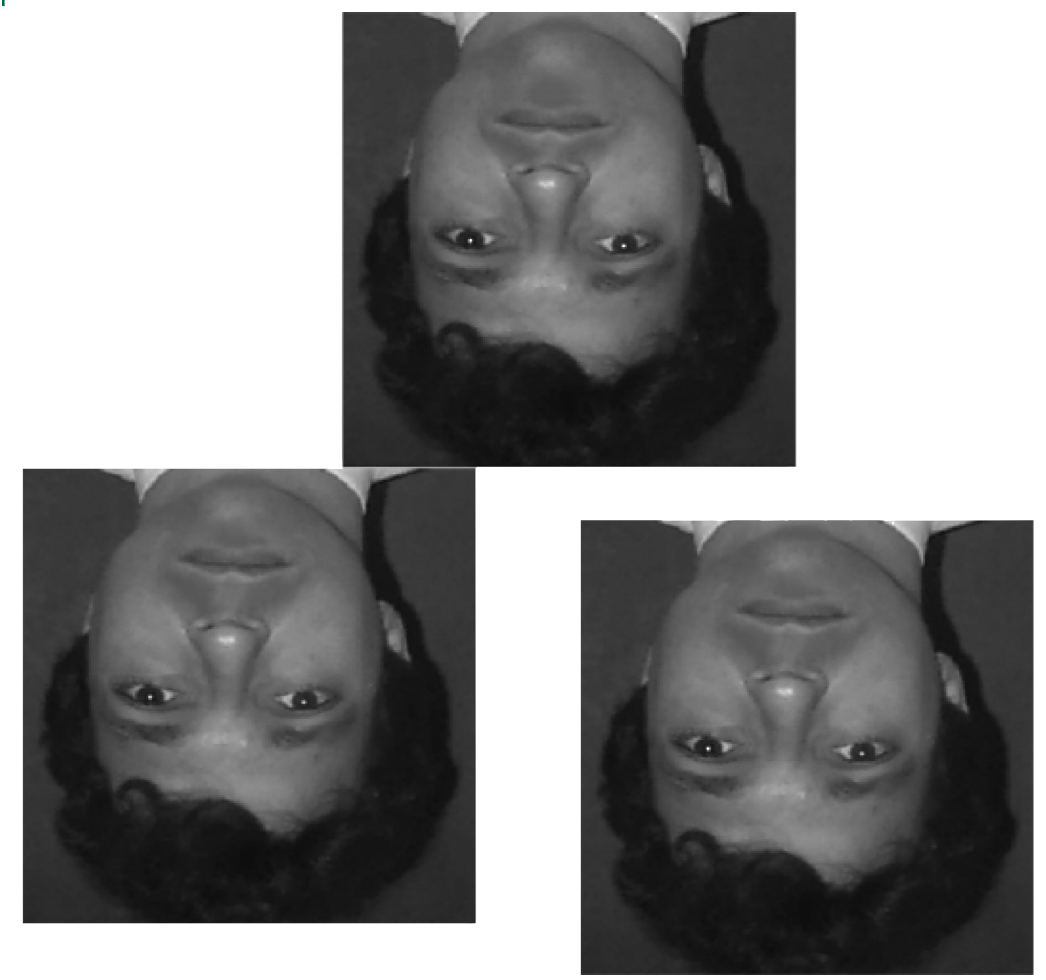

The subject has 2 seconds to decide which of the three stimuli differs from the other two. In this example from the inverted block, the upper face has a shorter nose-to-mouth distance.

were no significant inversion effects for either eye position or eye color, there was a far greater inversion effect for mouth position $(t=9.59, p<$ $0.0001)$ than for mouth color $(t=3.31, p<$ 0.002). These findings thus replicate our prior data showing that inversion affects perception of mouth position more than perception of mouth features or eye position. ${ }^{38,57}$

Contrasts between the subject groups. There was a main effect for group $\left(\mathrm{F}^{2,32}=24.5, p<0.0001\right)$. The SDD-2 group performed worse than either controls $(\mathrm{t}=6.87, p<0.0001)$ or the SDD-1 group $(t=3.79, p=0.0006)$. The SDD-1 group also performed slightly worse than the controls $(\mathrm{t}=2.26, p<0.04)$. There was a significant interaction between group and face part $\left(\mathrm{F}^{2,32}=3.26\right.$, $p=0.04)$, due to a larger difference between eye and mouth scores in the controls $(\mathrm{t}=5.53, p<$ $0.0001)$ and the SDD-1 group ( $t=4.79, p<$ $0.0001)$, compared to the SDD-2 group $(\mathrm{t}=3.25$, $p<0.002)$. There was a significant interaction between group and orientation $\left(\mathrm{F}^{2,32}=6.33, p<\right.$ $0.003)$. Again, this was due to a larger inversion effect for controls $(t=5.21, p<0.0001)$ and the SDD-1 group $(t=4.28, p<0.0001)$ than for the SDD-2 group $(t=1.36$, NS). No other interactions with group were significant.
Thus, the SDD-1 group, with normal famous face recognition, showed only relatively minor decrements in accuracy relative to controls and produced a pattern of results highly similar to those of controls, with similar scores for upright faces, a greater inversion effect for mouth position than mouth color, and no inversion effect for eye changes (figure 3 ).

In contrast, the SDD-2 group, with impaired famous face recognition, was significantly impaired. The significant interactions suggest that the SDD-2 group may also differ in the pattern of their results. However, the results in figure 3 show that there is no absolute sparing of processing for inverted faces, feature color, or mouth changes. Accuracies for all of these are depressed, just like those for the processing of upright faces, feature position, and eye changes. Is there relative sparing of these processes? Although the significant interactions may suggest this, such an interpretation is complicated by floor effects, particularly for perception of mouth position in inverted faces, which is already near chance in the normal and SDD-1 subjects.

To examine the possibility of relative sparing, we normalized the data of each subject by dividing their data by their score for discriminating upright eye position. We repeated the ANOVA on these normalized data. This ANOVA showed no significant effect of group and no significant interaction involving group. Thus the pattern of results in the normalized data is no different in SDD-2 than in the controls and in SDD-1. Furthermore, an ANOVA on the non-normalized data of the SDD-2 group alone showed a significant interaction between orientation and face part $\left(\mathrm{F}^{1,15}=7.44, p<0.008\right)$, with greater inversion effect for the mouth $(t=2.80, p=0.006)$ than the eyes $(t=1.06, N S)$ and a trend toward significance for the interaction of orientation and type of change $\left(\mathrm{F}^{1,15}=3.18, p=0.08\right)$, with greater inversion effect for position ( $t=2.13, p=$ $0.04)$ than for color $(t=0.39$, NS). This essentially reproduces the qualitative effects of the type of change and face part in the inversion effect of the SDD-2 group as in that of the other two groups.

Finally, to exclude a potential nonspecific effect of fatigue in our subjects with SDD, we compared for each subject the accuracy rate in the first half vs the second half of trials in each block. Considering all subjects with SDD, the difference between the halves was 0.01 [SD 0.08, $\mathrm{t}(23)=$ $0.78, \mathrm{NS}$ ] for upright trials and 0.02 [SD 0.08 , $\mathrm{t}(23)=1.20, \mathrm{NS}]$ for inverted trials. For SDD-2 
Figure $3 \quad$ Results

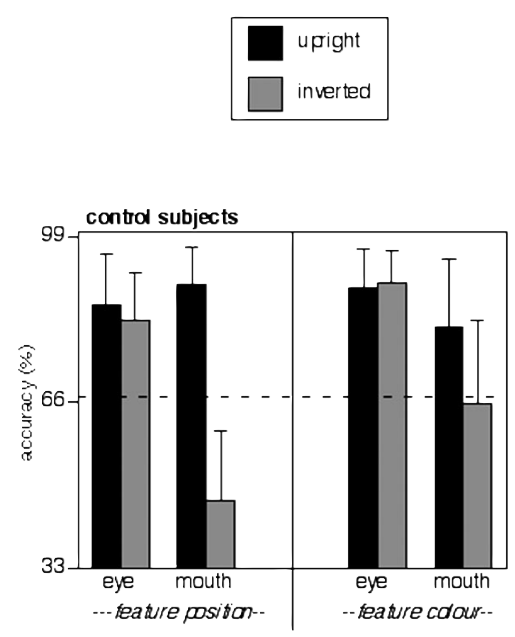

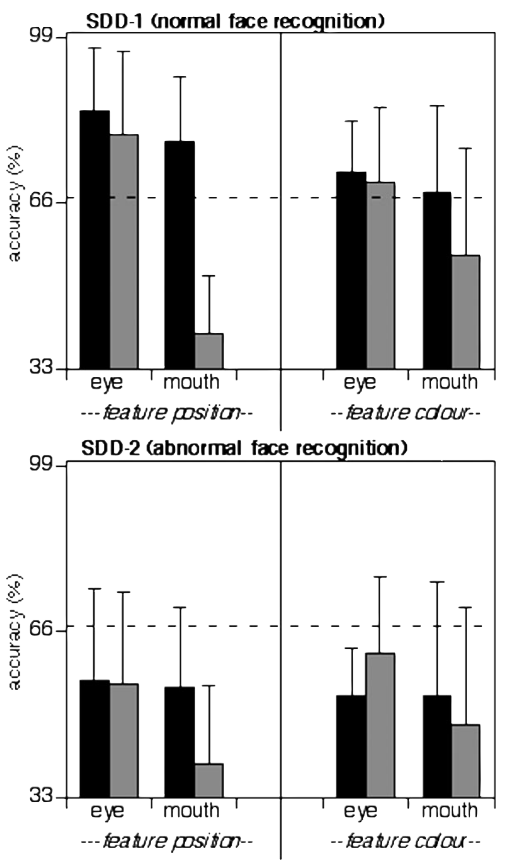

Left graph shows control data, top right graph shows data for the SDD-1 group (with normal famous face recognition) and the bottom right graph shows data for the SDD-2 group (with impaired famous face recognition). Black bars represent accuracy for upright faces and gray bars represent accuracy for inverted faces. The left halves of all graphs show data for configuration perception (i.e., feature position), the right halves the data for feature color perception. Error bars show one SD. The dashed lines indicate $67 \%$ correct, a threshold value that is halfway between chance performance (33\% correct) and perfect performance.

subjects alone, the difference was 0.01 [SD 0.10, $\mathrm{t}(15)=0.53$, NS] for upright trials, and $0.03[\mathrm{SD}$ $0.09, \mathrm{t}(15)=1.23$, NS] for inverted trials. Thus there was no significant difference in accuracy between the start and the end of the experiment, indicating that fatigue did not affect the findings.

DISCUSSION As expected, subjects with SDD-1, who recognized famous faces as well as controls, showed a similar pattern of results for facial perception to controls. More surprising was the fact that they had slightly lower overall accuracy on these tests. The finding that they perform slightly worse than controls on tests of face perception despite actually outperforming controls on tests of famous face discrimination ${ }^{49}$ might suggest that they have a mild perceptual defect, for which they compensate in some other fashion to achieve their superior famous face recognition scores. However, this is only speculative. The tests of face perception in this report differ from those used to test face recognition in several ways, such as being time-limited and involving 10 times as many trials, so that problems with nonspecific factors such as processing speed or sustained attention may also account for the discrepancy.
Also as predicted, subjects with SDD-2, who are impaired on famous face recognition, are impaired on these discriminative tests of face perception. More important, though, was the issue of whether the pattern of their deficit conformed to one of the hypothesized patterns of selective impairment we were evaluating. The answer, in both absolute and relative terms, appears to be no.

First, the prediction that subjects with SDD-2 should be more impaired on upright than inverted faces is based on the dual-route hypothesis. ${ }^{41}$ This states that upright faces have access to an expert face-processing system that has acquired an orientation dependency following years of exposure to predominantly upright faces, with the consequence that inverted faces can only be processed by a more generic object recognition route. The prediction would then be that, if such an orientation-dependent expert face processing system is lost, then both upright and inverted faces would be processed by the same generic object recognition mechanism. Hence one should find that the processing of inverted faces by subjects with SDD-2 should be similar to controls (since in both groups processing of inverted faces occurs in the same generic object recognition systems) and that in subjects with SDD-2 the processing of upright faces should be similar to that of inverted faces.

Neither proved true. Subjects with SDD-2 were also impaired at processing inverted faces, and the ANOVA of their data alone showed significant interactions between orientation and face part, indicating that they still show an advantage for upright faces. Indeed, within the smaller range of variation in subjects with SDD-2, the pattern of inversion effects across the four possible changes resembled those of the control subjects and subjects with SDD-1. Hence the results from the orientation data do not support the loss of an expert mechanism that operates exclusively on upright faces. The conclusion that residual inversion effects for face perception are still present in SDD-2 parallels other reports of preserved inversion effects for face recognition ${ }^{58-60}$ in autism. Likewise, autism does not eliminate the Thatcher illusion, ${ }^{61}$ in which the bizarre appearance of a face containing an upside-down set of mouth and eyes is not appreciated when the entire image is inverted. ${ }^{62}$

Also of note, there was no evidence of an inverted inversion effect ${ }^{42,43}$ - that is, there were no changes for which perception was significantly more accurate with inverted than with upright faces. The inverted inversion effect is considered strong support of the dual-route hypothesis and 
the existence of separate face and object processing mechanisms. ${ }^{63}$ In the autism literature, a related finding with similar implications is the report that autistic subjects are superior to controls in processing expression in inverted faces but inferior to controls with upright faces. ${ }^{64}$ Our subjects with SDD-2 show neither of these effects for any facial change. Their performance with inverted faces was not better than their own upright face performance and not better than the inverted face performance of controls.

Second, our results are clear concerning the perception of configuration-or more specifically, second-order spatial relations. ${ }^{65}$ There is no evidence of a selective deficit for processing face configuration, as both configuration and feature color are affected similarly in the SDD-2 group. This resembles our findings with two patients with acquired prosopagnosia, who had difficulty perceiving both configuration and eye color, but contrasts with two others, who had selective involvement of configuration perception sparing perception of eye color. ${ }^{35}$ Our speculation in that report was that, while deficits in perceiving facial structure may be associated with lesions in the region of the fusiform gyrus - an area whose status is of intense interest in autism, ${ }^{1,66}$ as we described in the Introduction-additional problems with discriminating eye color in the first two patients may be related to more extensive peri-striate damage. Whether more extensive visual dysfunction is present in SDD-2 is uncertain. However, there are prior reports that autistic children with face processing deficits also have impairments in the processing of nonfacial visual stimuli. ${ }^{67,68}$

Other types of configural processing have also been assessed in autistic subjects in other studies. Holistic face processing has been assessed by comparing the recognition of facial features presented in isolation, with additional face parts or in the context of the whole face: the findings support residual configural processing but possibly combined with abnormally enhanced processing of local elements. ${ }^{59,60}$ This is consistent with the results of an investigation of global vs local processing in autism using hierarchical letters, which has also suggested residual ability to derive configurations combined with interference from a bias toward processing local elements. ${ }^{69}$ Our analysis would support the assertion that defective configural processing is not the critical abnormality in face recognition in these subjects: we find one SDD group with equally preserved processing of features and second-order spatial rela- tions, and another with equally impaired processing of these different aspects.

Third, the prediction that SDD-2 subjects should be more impaired on eye changes than mouth changes is based on fixation and behavior studies showing that the eye region receives less attention in autism than in controls. ${ }^{33,44,45,59}$ The importance of the eye region in social communication $^{70}$ and person identification ${ }^{71}$ implies that failure to process this facial region would have significant implications for behavior. Selective failure to attend to the eyes should lead to an interaction between group and face part, with subjects with SDD having disproportionately greater difficulty with eyes than mouth relative to controls. When the data were normalized to take into account reductions in eye position discrimination, no such interaction was found. Figure 3 shows that, with upright faces, the SDD-2 group is impaired to a similar degree at perceiving changes in both the eyes and the mouth. Hence there are insufficient grounds for concluding that there is a selective or disproportionate failure to process the eyes in our test. This conclusion may be more consistent with other fixation studies showing that autistic subjects either avoid looking at all core facial features ${ }^{72}$ or have normal fixation distributions within facial elements, ${ }^{73}$ and a behavioral study showing that autistic patients exhibit the normal pattern of attending more to the eyes than the mouth. ${ }^{74}$ However, we caution that our subjects were given trial examples and pre-test instructions that changes could occur in the eye or mouth region. Without such a priori expectations, it is possible that they would fail to process the eye region as well as they did the mouth region. While our results may not speak to more naturalistic conditions, ${ }^{45}$ they nevertheless show that the potential capacity to process the eye region is as good as the capacity to process the mouth region, in both SDD-1 and SDD-2 groups.

All told, our results show that there is indeed a failure of face perception in the SDD-2 group, with poor face recognition skills, a result consistent with prior studies showing deficits in facematching tasks in autism and Asperger disorder. ${ }^{67,75-77}$ Why face processing is significantly more affected in SDD-2 than SDD-1 remains unclear, but the results imply a perceptual heterogeneity that may have implications for rehabilitative and genetic studies. However, despite the face-processing deficit in SDD-2, there is no convincing evidence that this impairment is selective for configuration, for upright faces, or for the eye region. As such, these data are difficult to rec- 
oncile with hypotheses that face processing impairments in SDD are characterized by loss of an expert mechanism selective for upright faces and specialized for configuration perception. Rather, the data suggest a general impairment of facial processing regardless of orientation, face part, or type of information, which qualitatively preserves the normal pattern of efficiency across these factors. Results showing quantitative reductions but not qualitative changes in the pattern of performance are reminiscent of some other recent findings, such as the fact that, while event-related potentials to faces are slowed in Asperger disorder, the normal advantage for whole faces over face parts and for eyes over mouths is preserved. ${ }^{78}$

This conclusion does not necessarily imply that subjects with SDD have preserved face expertise, however. Our pattern of results might be predicted from more recent computational models of face perception that argue that there is no neurophysiologic evidence for dichotomous (i.e., "dualroute") processing mechanisms, and that inversion effects likely evolve through the experience-dependent refinement of tuning curves of neurons that respond to faces, rather than a switch in processing strategy. ${ }^{79,80}$ It may also be consistent with other recent data showing that inversion effects are found not only for feature configuration but also for other facial properties, such as feature shape and external contour..$^{57,81}$ Thus, the face processing deficits we find in SDD-2 may prove informative in the debate about the nature of face processing, and together with other data prompt revisions of our concepts of what it means to be a face expert.

Received June 16, 2006. Accepted in final form April 2, 2007.

\section{REFERENCES}

1. Jemel B, Mottron L, Dawson M. Impaired face processing in autism: fact or artifact? J Autism Dev Disord 2006 (epub).

2. Kracke I. Developmental prosopagnosia in Asperger syndrome: presentation and discussion of an individual case. Dev Med Child Neurol 1994;36:873-886.

3. McConachie H. Developmental prosopagnosia, a single case report. Cortex 1976;12:76-82.

4. Barton J, Cherkasova M, Press D, Intriligator J, O'Connor M. Developmental prosopagnosia: a study of three patients. Brain Cogn 2003;51:12-30.

5. Pietz J, Ebinger F, Rating D. Prosopagnosia in a preschool child with Asperger syndrome. Dev Med Child Neurol 2003;45:55-57.

6. Andersen E, Dunlea A, Kekelis L. Blind children's language: resolving some differences. J Child Language 1984;11:645-664.

7. Fraiberg S. Insights from the blind. London: Souvenir Press, 1977.
8. Cass H, Sonksen P, McConachie H. Developmental setback in severe visual impairment. Arch Dis Childhood 1994;70:192-196.

9. McAlpine L, Moore C. The development of social understanding in children with visual impairments. J Vis Impairment Blindness 1995;89:349-358.

10. Brown R, Hobson R, Lee A. Are there "autistic-like" features in congenitally blind children ? J Child Psychol Psychiatry 1997;38:693-703.

11. Goodman R, Ashby L. Delayed visual maturation and autism. Dev Med Child Neurol 1990;32:808-819.

12. Mottron L, Mineau S, Décarie M, et al. Visual agnosia with bilateral temporo-occipital brain lesions in a child with autistic disorder: a case study. Dev Med Child Neurol 1997;39:699-705.

13. Jambaque I, Mottron L, Ponsot G, Chiron C. Autism and visual agnosia in a child with right occipital lobectomy. J Neurol Neurosurg Psychiatry 1998;65:555560.

14. Elgar K, Campbell R. The development of faceidentification skills: what lies behind the face module? Infant Child Dev 2001;10:25-30.

15. Grelotti DJ, Gauthier I, Schultz RT. Social interest and the development of cortical face specialization: what autism teaches us about face processing. Dev Psychobiol 2002;40:213-225.

16. Trepagnier C. Autism etiology: a face-processing perspective. Brain Cogn 1998;37:158-160.

17. Elgar K, Campbell R. Annotation: the cognitive neuroscience of face recognition: implications for developmental disorders. J Child Psychol Psychiatry 2001;42: 705-717.

18. Carey S. Becoming a face expert. Phil Trans R Soc Lond B Biol Sci 1992;335:95-103.

19. Swettenham J, Baron-Cohen S, Charman T, et al. The frequency and distribution of spontaneous attention shifts between social and nonsocial stimuli in autistic, typically developing, and non-autistic developmentally delayed infants. J Child Psychol Psychiatry 1998;39: 747-753.

20. Trepagnier C, Sebrechts MM, Peterson R. Atypical face gaze in autism. Cyberpsychol Behav 2002;5:213217

21. Boucher J, Lewis V, Collis G. Familiar face and voice matching and recognition in children with autism. J Child Psychol Psychiatry 1998;39:171-181.

22. Boucher J, Lewis V. Unfamiliar face recognition in relatively able autistic children. J Child Psychol Psychiatry 1992;33:843-859.

23. Dawson G, Carver L, Meltzoff AN, Panagiotides H, McPartland J, Webb SJ. Neural correlates of face and object recognition in young children with autism spectrum disorder, developmental delay, and typical development. Child Dev 2002;73:700-717.

24. Bailey A, Braeutigam S, Jousmäki V, Swithenby S. Abnormal activation of face processing systems at early and intermediate latency in individuals with autism spectrum disorder: a magnetoencephalographic study. Eur J Neurosci 2005;21:2575-2585.

25. Haxby J, Hoffman E, Gobbini M. The distributed human neural system for face perception. Trends Cogn Sci 2000;4:223-233.

26. Kanwisher N. Domain specificity in face perception. Nat Neurosci 2000;3:759-763. 
27. Tarr MJ, Gauthier I. FFA: a flexible fusiform area for subordinate-level visual processing automatized by expertise. Nat Neurosci 2000;3:764-769.

28. Schultz RT, Gauthier I, Klin A, et al. Abnormal ventral temporal cortical activity during face discrimination among individuals with autism and Asperger syndrome. Arch Gen Psychiatry 2000;57:331-340.

29. Critchley HD, Daly EM, Bullmore ET, et al. The functional neuroanatomy of social behaviour: changes in cerebral blood flow when people with autistic disorder process facial expressions. Brain 2000;123:2203-2212.

30. Pierce K, Muller RA, Ambrose J, Allen G, Courchesne E. Face processing occurs outside the fusiform 'face area' in autism: evidence from functional MRI. Brain 2001;124:2059-2073.

31. Hadjikhani N, Joseph R, Snyder J, et al. Activation of the fusiform gyrus when individuals with autism spectrum disorder view faces. Neuroimage 2004;22:11411150.

32. Pierce $\mathrm{K}$, et al. The brain response to personally familiar faces in autism: Findings in fusiform activity and beyond. Brain 2004;127:2703-2716.

33. Dalton K, Nacewicz B, Johnstone T, et al. Gaze fixation and the neural circuitry of face processing in autism. Nat Neurosci 2005;8:519-526.

34. Rotshtein P, Henson R, Treves A, Driver J, Dolan R. Morphing Marilyn into Maggie dissociates physical and identity face representations in the brain. Nat Neurosci 2005;8:107-113.

35. Barton J, Press D, Keenan J, O'Connor M. Lesions of the fusiform face area impair perception of facial configuration in prosopagnosia. Neurology 2002;58:7178.

36. Rhodes G, Brake S, Atkinson A. What's lost in inverted faces ? Cognition 1993;47:25-57

37. Leder $\mathrm{H}$, Bruce $\mathrm{V}$. When inverted faces are recognized: the role of configural information in face recognition. Quarterly J Exp Psychol 2000;53A:513-536.

38. Barton J, Keenan J, Bass T. Discrimination of spatial relations and features in faces: effects of inversion and viewing duration. Br J Psychol 2001;92:527-549.

39. Valentine T. Upside-down faces: a review of the effect of inversion upon face recognition. Br J Psychol 1988; 79:471-491.

40. Rossion B, Gauthier I. How does the brain process upright and inverted faces? Behav Cogn Neurosci Reviews 2002;1:262-274.

41. Bartlett J, Searcy J. Inversion and configuration of faces. Cogn Psychol 1993;25:281-316.

42. Farah M, Wilson K, Drain H, Tanaka J. The inverted face inversion effect in prosopagnosia: evidence for mandatory face-specific perceptual mechanisms. Vision Res 1995;35:2089-2093.

43. de Gelder B, Bachoud-Levi A, Degos J. Inversion superiority in visual agnosia may be common to a variety of orientation polarised objects besides faces. Vision Res 1998;38:2855-2861.

44. Langdell T. Recognition of faces: a approach to the study of autism. J Child Psychol Psychiatry 1978;19: 255-268.

45. Klin A, Jones W, Schultz R, Volkmar F, Cohen D. Visual fixation patterns during viewing of naturalistic social situations as predictors of social competence in individuals with autism. Arch Gen Psychiatry 2002;59: 809-816.

46. Baron-Cohen S, Wheelwright S, Hill J, Raste Y, Plumb I. The "Reading the Mind in the Eyes" Test revised version: a study with normal adults, and adults with Asperger syndrome or high-functioning autism. J Child Psychol Psychiatry 2001;42:241-251.

47. Barton J, Radcliffe N, Cherkasova M, Edelman J, Intriligator J. Information processing during face recognition: the effects of familiarity, inversion and morphing on scanning fixations. Perception 2006 (in press).

48. Caldara R, Schyns P, Mayer E, Smith M, Gosselin F, Rossion B. Does prosopagnosia take the eyes out of face representations? Evidence for a defect in representing diagnostic facial information following brain damage. J Cogn Neurosci 2005;17:1652-1666.

49. Barton J, Cherkasova M, Hefter R, Cox T, O'Connor M, Manoach D. Are patients with social developmental disorders prosopagnostic? Perceptual heterogeneity in the Asperger and socio-emotional processing disorders. Brain 2004;127:1706-1716.

50. Lord C, Rutter M, Couteur A. Autism diagnostic interview-revised: a revised version of a diagnostic interview for caregivers of individuals with possible pervasive developmental disorders. J Autism Dev Disord 1994;24:659-685.

51. Hefter R, Manoach D, Barton J. Perception of facial expression and facial identity in patients with developmental social processing disorders. Neurology 2005;65: 1620-1625.

52. Warrington E. Warrington Recognition Memory Test. Los Angeles: Western Psychological Services, 1984.

53. Benton A, van Allen M. Prosopagnosia and facial discrimination. J Neurol Sci 1972;15:167-172.

54. Barton J, Cherkasova M, O'Connor M. Covert recognition in acquired and developmental prosopagnosia. Neurology 2001;57:1161-1167.

55. Barton J, Cherkasova M. Face imagery and its relation to perception and covert recognition in prosopagnosia. Neurology 2003;61:220-225.

56. Searcy J, Bartlett J. Inversion and processing of component and spatial-relational information in faces. J Exp Psychol 1996;22:904-915.

57. Malcolm G, Leung C, Barton J. Regional variation in the inversion effect for faces: different patterns for feature shape, spatial relations, and external contour. Perception 2004;33:1221-1231.

58. Teunisse J-P, de Gelder B. Do autistics have a generalized face processing deficit ? Int J Neurosci 1994;77:110.

59. Joseph R, Tanaka J. Holistic and part-based face recognition in children with autism. J Child Psychol Psychiatry 2003;44:529-542.

60. Lahaie A, Mottron L, Arguin M, Berthiaume C, Jemel B, Saumier D. Face perception in high-functioning autistic adults: evidence for superior processing of face parts, not for a configural face-processing deficit. Neuropsychology 2006;20:30-41.

61. Rouse H, Donnelly N, Hadwin J, Brown T. Do children with autism perceive second-order relational features? The case of the Thatcher illusion. J Child Psychol Psychiatry 2004;45:1246-1257. 
62. Thompson P. Margaret Thatcher: a new illusion. Perception 1980;9:483-484.

63. Farah M, Wilson K, Drain M, Tanaka J. What is "special” about face perception? Psychol Review 1998;105: 482-498.

64. Hobson R, Ouston J, Lee A. What's in a face? The case of autism. Br J Psychol 1988;79:441-453.

65. Maurer D, Legrand R, Mondloch C. The many faces of configural processing. Trends Cogn Sci 2002;6:255-260.

66. Sasson N. The development of face processing in autism. J Autism Dev Disord 2006;36:381-394.

67. Davies S, Bishop D, Manstead A, Tantam D. Face perception in children with autism and Asperger's syndrome. J Child Psychol Psychiatry 1994;35:1033-1057.

68. Volkmar F, Sparrow S, Rende R, Cohen D. Facial perception in autism. J Child Psychol Psychiatry 1989;30: 591-598.

69. Behrmann M, Avidan G, Leonard G, et al. Configural processing in autism and its relationship to face processing. Neuropsychologia 2006;44:110-129.

70. Baron-Cohen S, Jolliffe T, Mortimore C, Robertson M. Another advanced test of theory of mind: evidence from very high functioning adults with autism or Asperger syndrome. J Child Psychol Psychiatry 1997;38: 813-822.

71. Gosselin F, Schyns P. Bubbles: a technique to reveal the use of information in recognition tasks. Vision Res 2001;41:2261-2271.

72. Pelphrey KA, Sasson NJ, Reznick JS, Paul G, Goldman BD, Piven J. Visual scanning of faces in autism. J Autism Dev Disord 2002;32:249-261.

73. van der Geest JN, Kemner C, Verbaten MN, van Engeland H. Gaze behavior of children with pervasive de- velopmental disorder toward human faces: a fixation time study. J Child Psychol Psychiatry 2002;43:669678.

74. Bar-Haim Y, Shulman C, Lamy D, Reuveni A. Attention to eyes and mouth in high-functioning children with autism. J Autism Developmental Disord 2006 (epub).

75. Tantam D, Monaghan L, Nicholson H, Stirling J. Autistic children's ability to interpret faces: a research note. J Child Psychol Psychiatry 1989;30:623-630.

76. Szatmari P, Tuff L, Finlayson M, Bartolucci G. Asperger's syndrome and autism: neurocognitive aspects. J Am Acad Child Adolesc Psychiatry 1990;29: 130-136.

77. Klin A, Sparrow SS, de Bildt A, Cicchetti DV, Cohen DJ, Volkmar FR. A Normed study of face recognition in autism and related disorders. J Autism Dev Disord 1999;29:499-508.

78. O’Connor K, Hamm J, Kirk I. Neurophysiological responses to face, facial regions and objects in adults with Asperger's syndrome: an ERP investigation. J Psychophysiol 2007 (epub).

79. Riesenhuber M, Poggio T. Hierarchical models of object recognition in cortex. Nat Neurosci 1999;2:10191025.

80. Rosen E. Face representation in cortex: studies using a simple and not so special model. Electrical Engineering and Computer Science. Cambridge: MIT, 2003:75.

81. Riesenhuber M, Jarudi I, Gilad S, Sinha P. Face processing in humans is compatible with a simple shape-based model of vision. Proc Roy Soc Lond B (suppl) 2004.

\section{Do You Have What It Takes to Be a Neurology Advocate?}

Since 2003, the award-winning Donald M. Palatucci Advocacy Leadership Forum has trained 150 AAN members to become stronger advocates for their patients and profession. We want to empower you to create change. The next Forum will be held January 10-13, 2008, at the St. Regis Resort in Ft. Lauderdale, Florida. If you have the vision, the dedication, and the determination, go to the AAN Website at www.aan.com/palfad and apply today. 